\title{
THE SPECTRA OF INTESTINAL PARASITIC INFECTIONS AFFECTING PATIENTS ATTENDING A TERTIARY CARE CENTER IN WESTERN UTTAR PRADESH
}

\author{
PREM PRAKASH MISHRA ${ }^{1 *}$, ANIL KUMAR ${ }^{1}$, DEEPAK UPADHYAY ${ }^{2}$, AMIT GARG $^{1}$, SHRISTI SHARMA ${ }^{1}$
}

${ }^{1}$ Department of Microbiology, LLRM Medical College, Meerut, Uttar Pradesh, India. ${ }^{2}$ Department of Preventive and Social Medicine, Rohilkhand Medical College and Hospital, Bareilly, Uttar Pradesh, India. Email: prem6284@gmail.com

Received: 06 March 2021, Revised and Accepted: 10 April 2021

\section{ABSTRACT}

Objective: Intestinal parasitic infection is a burgeoning health issue, especially in developing countries owing to low socioeconomic conditions, poor sanitation, poor personal hygiene, and lack of access to potable drinking water. This study aims to determine the prevalence of different intestinal parasites among the patients.

Methods: This cross-sectional study was conducted among 470 patients attending our hospital from October 2018 to September 2019 . Specimens were collected and examined macroscopically and microscopically using concentration methods and modified Ziehl-Neelsen staining for coccidian parasites.

Results: Out of the 470 patients, prevalence of intestinal infections was $4.89 \%$. The helminthic infections were more common (52.17\%), which was topped by Hookworm infection (26.09\%) followed by Ascariasis (13.04\%). Among the protozoa, Giardia lamblia (26.09\%) was the most common, followed by Entamoeba histolytica (17.39\%). The parasitic infections were more in female (5.62\%) than male (4.19\%) and highest in the pediatric age group and between 51 and 60 years.

Conclusion: The prevalence of intestinal parasitic infections is decreasing due to increasing awareness about sanitation, effects of open defecation, safe drinking water, and personal hygiene. However, the need of intervallic monitoring of intestinal parasitic infections is necessary.

Keywords: Parasitic, Hookworm, Giardia lamblia, Coccidian, Modified Z-N staining.

(C) 2021 The Authors. Published by Innovare Academic Sciences Pvt Ltd. This is an open access article under the CC BY license (http://creativecommons.org/ licenses/by/4.0/) DOI: http://dx.doi.org/10.22159/ajpcr.2021v14i6.41467. Journal homepage: https://innovareacademics.in/journals/index.php/ajpcr

\section{INTRODUCTION}

Intestinal parasitic infections are widely strewn throughout the globe, and they are continued to be a cause of health concern in developing countries. The disease-causing parasites may cause serious infections and occasionally death of hosts, especially in immunocompromised hosts. These infections are one of the major health perils which have affected approximately 3.5 billion people and caused disease in around 450 million people and the majority is constituted by children [1]. The reports from the past state that around 2 lakhs deaths per annum are attributed to these infections, chiefly in developing countries [2]. The prevalence of these infections is variable with respect to the different regions of the world, which predominantly depends on factors such as personal and community hygiene, poor sanitary facilities, geographic and socioeconomic factors, relatively humid areas, poverty, malnutrition, and high population density [3]. The infections such as Amoebiasis, Giardiasis, Trichuriasis, Hookworm, and Hymenolepis nana infection are the most common infections leading to various complications such as iron deficiency anemia, chronic diarrhea, portal hypertension, and impaired physical development in children along with other comorbidities [4]. Several reports from different parts of India have revealed a variable etiology of intestinal parasitic infection among different groups of population. It has become imperative to be acquainted with the disease burden of parasitic infestation in the population residing in this area. No such studies for intestinal parasitic infections were carried out among the patients attending this tertiary care center. Hence, this study was conducted to determine the spectrum of intestinal parasites affecting the patients attending the tertiary care center.

\section{METHODS}

This cross-sectional study was conducted in the Department of Microbiology, LLRM, Medical College, Meerut from October 2018 to
September 2019 among 470 patients attending the outpatient and inpatient department of various clinical departments and emergency. The stool specimens from the patients attending our tertiary care hospital were screened after the approval from the Ethics Committee of the institute and obtaining written informed consent from the patient or their guardian. The stool samples were collected in universal container and marked with time of collection, date of sampling, name of the patient, age, and sex. The samples were evaluated for macroscopic as well as microscopic examination within few hours of sample collection. The macroscopic examination included color, consistency, presence of mucus, blood, parasites, or its segments. Microscopic examination was done by examination of normal saline and iodine wet mount to detect the ova and cyst of the parasites as well as erythrocytes and pus cells. Formol-ether concentration technique was adopted for re-examination of negative samples. Protozoa and helminths were identified according to their morphological details [5]. Modified Ziehl-Neelsen (Z-N) staining was done on smears prepared from the fresh stool specimen. The slides were screened under different objectives for identification of the coccidian parasites such as Cystoisospora belli, Cryptosporidium spp., and Cyclospora cayetanensis [6]. The data analysis and validation were carried out by using SPSS version 24 software. The data were represented in terms of percentage, mean and median. All $p<0.05$ were considered statistically significant, while $p$ value $(p>0.05)$ was considered insignificant.

\section{RESULTS}

A total of 470 patient's stool specimens were studied in the current study for detection of different pathogenic intestinal parasites. The age group of the patient ranged from 1 day to $>90$ years. The majority of the patients $n=193(41.06 \%)$ belonged to the pediatric age group (0-18 years) followed by the age group (19-36 years). The positivity 
in microscopy was found to be $4.68 \%$ which was more $(6.22 \%)$ in the pediatric $(0-18)$ age group, which is statistically insignificant $(p>0.05)$, as shown in Table 1. The male-to-female ratio was 1.9375:1. The positivity of finding the parasites was more $5.62 \%(n=9 / 160)$ in females as compared to males $4.19 \%(n=13 / 310)$ (Table 1$)$. There is no statistical difference in positivity in male and female in relation to distribution in the different age group $(p>0.05)$.

Among the 470 stool specimens, the positivity of occult blood was found to be $13.99 \%(n=40 / 286)$. The age group with the highest occult blood positivity $50 \%(n=3 / 6)$ was found to be in 73-90 years followed by $19-36$ years, $17.86 \%(n=15 / 84)$, as shown in Table 2 . The intestinal parasites were mostly detected from the pediatric age group (6.22\%) and age group 55-72 years (6.25\%) (Table 2). Microscopic detection in the different age group was statistically insignificant, whereas a high proportion of individuals of the older age group were found to be statistically significantly positive $(p<0.05)$.

Out of the 23 isolates, the isolation of helminths (52.17\%) was more as compared to the protozoan $(43.48 \%)$ and coccidian parasite $(4.35 \%)$. Giardia lamblia (26.09\%) was the most commonly detected protozoa followed by Entamoeba histolytica (17.39\%). Among the intestinal helminths, Hookworm (26.09\%) tops the list followed by Ascaris lumbricoides (13.04\%). Among coccidian parasites, the only isolate was C. belli (4.35\%), while mixed infection was observed which was H. nana and Trichuris trichiura. The distribution of the intestinal pathogenic parasites is depicted in Fig. 1, while (Fig. 2a-d) and (Fig. 3a-d) shows the microscopic view of the isolated parasites.

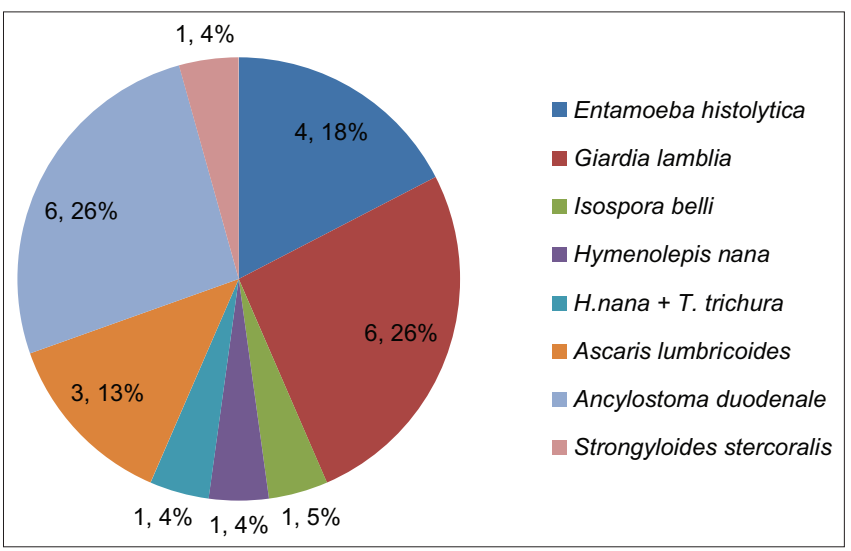

Fig. 1: Frequency of parasites screened from stool specimen

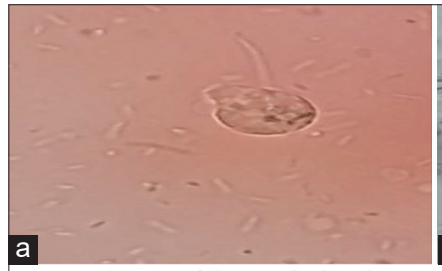

Trophozoite of Entamoeba histolytica

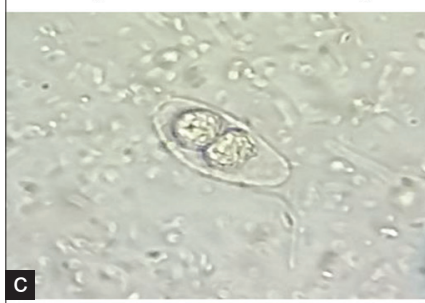

Oocyst of Cystoisospora belli

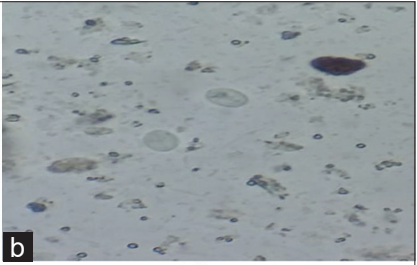

Cyst of Giardia lamblia

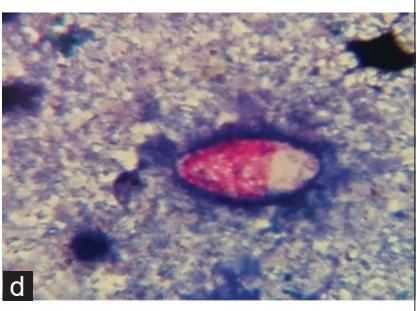

Modified Z-N Smear of Cystoisospora bellt

Fig. 2: (a-d) Pictures of different pathogenic enteric amoebae, flagellate, and coccidian

\section{DISCUSSION}

The risk of acquiring parasitic intestinal infections by human population varies significantly by region to region, communities, and even seasonal variation is also noticeable. It is well established that intestinal parasitic infections are closely related to poor sanitary habits and improper hygiene. Examination of wet mounts of stool and smears stained with modified Z-N technique is the standard technique used for detecting intestinal parasites but requires an experienced person for identifying the parasites. The current study revealed a prevalence of $4.89 \%$ of intestinal parasitic infection among people residing in this area. A quite similar prevalence of $6.68 \%$ was observed in a study from Rohtak [7], while a study from south India showed a very higher prevalence rate of $97.4 \%$ [8]. A slight higher prevalence of $11.2 \%$ has been reported from the neighboring state of Uttarakhand in 2014 [9]. On the other hand, prevalence of intestinal parasitic infections in neighboring countries Nepal and Sri Lanka has been reported as $29.4-34.56 \%$, respectively [10]. The wide range of variation in the prevalence of intestinal parasite infection may be owing to variability in factors such as quality of water supply, sanitation, and other environmental conditions. The low prevalence in the current study can be due to the increasing awareness regarding factors such as improved sanitation and quality of drinking water supply and improved cleanliness by movements like "Swachh Bharat Abhiyan".

The positivity of intestinal parasites was more $5.62 \%$ in females as compared to males $4.19 \%$, which is in accordance with the study by Kotian et al. [9]. Some studies showed male predominance [11,12]. This variation can be due to more involvement of females in outdoor activities like agriculture as compared to males nowadays. In the current study, the most common age group affected by intestinal parasites was the pediatric age group (6.22\%) and age group 55-72 years (6.22\%). This finding is in line with the study from Gujarat, in which the most common age group was 6-20 years [13].

In some of the past studies, protozoan infection is more prevalent as compared to helminthic infection [13,14], but in the current study, the helminthic infection (52.17\%) is more prevalent in contrast to protozoan (43.48\%) or coccidian infection (4.35\%) which is similar to the study conducted in Rajasthan and Gujarat $[15,16]$.

G. lamblia was the most common intestinal protozoan detected in our study accounting for $26.09 \%$ followed by E. histolytica, which were $17.39 \%$ which is in agreement with many past studies $[7,9,16,17]$. The route of transmission is through feco-oral route by ingestion of contaminated water and food as it a frequent environmental contaminant of water supply. Cysts of Giardia and E. histolytica have been isolated from water supplies in different parts of the world [18].
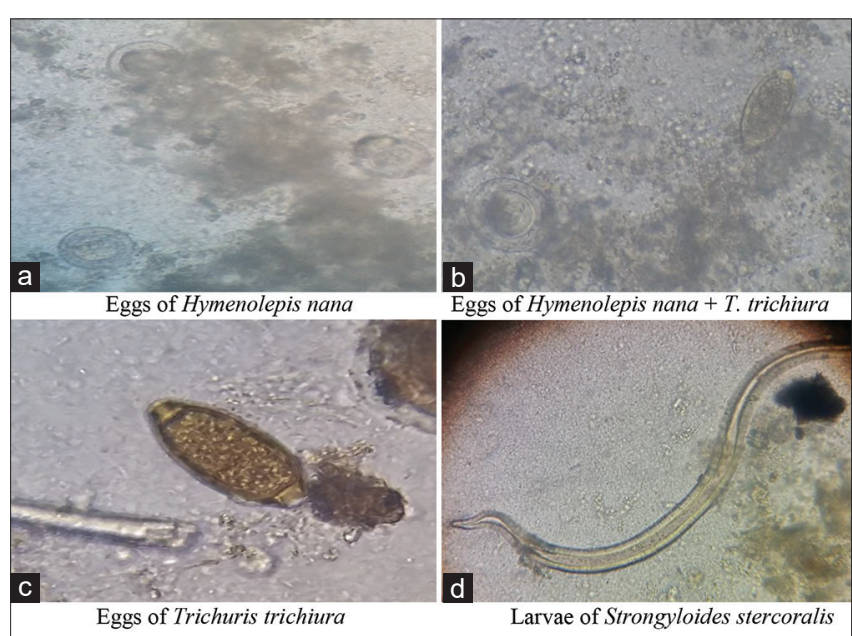

Figure 3: (a-d) Pictures of different eggs and larvae of pathogenic enteric helminths 
Table 1: Positivity of stool microscopy among different age group and sexes

\begin{tabular}{|c|c|c|c|c|c|c|c|}
\hline \multirow[t]{2}{*}{ Age group } & \multicolumn{3}{|l|}{ Males } & \multicolumn{3}{|l|}{ Females } & \multirow[t]{2}{*}{ Grand total (\%) } \\
\hline & Negative & Positive & Total & Negative & Positive & Total & \\
\hline $0-18$ & 112 & 5 & 117 & 70 & 6 & 76 & $193(41.06)$ \\
\hline $37-54$ & 52 & 3 & 55 & 28 & 1 & 29 & $84(17.87)$ \\
\hline $55-72$ & 34 & 2 & 36 & 11 & 1 & 12 & $48(10.21)$ \\
\hline $73-90$ & 4 & 0 & 4 & 2 & 0 & 2 & $6(1.28)$ \\
\hline$>90$ & 3 & 0 & 3 & 1 & 0 & 1 & $4(0.85)$ \\
\hline TOTAL & 297 & 13 & 310 & 150 & 9 & 160 & $470(100.00)$ \\
\hline
\end{tabular}

$\mathrm{p}=0.7096(\mathrm{p}>0.05)$

Table 2: Frequency of occult blood positivity and microscopic findings among different age groups

\begin{tabular}{llll}
\hline $\begin{array}{l}\text { Age } \\
\text { group }\end{array}$ & $\begin{array}{l}\text { Total number } \\
\text { of patients }\end{array}$ & $\begin{array}{l}\text { Patients with occult } \\
\text { blood positive }\end{array}$ & $\begin{array}{l}\text { OVA /Cyst/Oocyst/ } \\
\text { Larvae (\%) }\end{array}$ \\
\hline $0-18$ & 193 & 10 & $12(6.22)$ \\
$19-36$ & 135 & 15 & $4(2.96)$ \\
$37-54$ & 84 & 3 & $4(4.76)$ \\
$55-72$ & 48 & 9 & $3(6.25)$ \\
$73-90$ & 6 & 3 & $0(0.00)$ \\
$>90$ & 4 & 0 & $0(0.00)$ \\
p-value & & $\mathrm{p}=0.008(\mathrm{p}<0.05)$ & $\mathrm{p}=0.7186, \mathrm{p}>0.05$ \\
\hline
\end{tabular}

Among the intestinal helminths, prevalence of hookworm infection $(26.09 \%)$ was the highest and was significantly more in the adult population followed by A. lumbricoides (13.04\%). A similar high prevalence of hookworm infection has been reported from past studies $[9,19]$. The high rate of hookworm infection can be attributed to the fact that most of the people belong to rural areas and the prime occupation is agriculture, in which they have to walk barefooted in the fields. The other parasitic helminthic infections found in this study were trichuriasis, hymenolepiasis, and strongyloidiasis.

This study showed one case of $(4.54 \%)$ of mixed parasitic infection out of the 22 cases, which shows that the parasites can co-infect the individual causing serious health issues, which is also confirmed by other studies $[14,15]$. The results in this study showed a case of infection by the coccidian parasite $C$. belli; this is in line with the findings documenting the least diagnosis of $C$. belli/I. belli $[20,21]$. The disparity in various studies regarding the distribution of intestinal or coccidian parasitic etiology justifies that there is no explicit pattern in causing intestinal parasitic infections in individuals. However, it depends on geographical location, ethnicity, immune status, and the living conditions of the patients.

\section{CONCLUSION}

This study highlights a substantially low rate of intestinal parasitic infections, with other studies showing higher rates, which depends upon geographical factors and socioeconomic factors. Therefore, the current study urges the need and importance of intervallic monitoring of intestinal parasitic infections among immunocompetent as well as immunocompromised individuals so as to have an idea about the prevalent etiology of that region to combat morbidity and mortality.

\section{ACKNOWLEDGMENT}

We are particularly grateful for the assistance given by Mr. Manoj Kumar (Senior Laboratory Technician) during the study period.

\section{CONFLICTS OF INTEREST}

All authors declare no conflicts of interest.

\section{FUNDING}

There was no funding.

\section{REFERENCES}

1. Hotez PJ, Fenwick A, Savioli L, Molyneux DH. Rescuing the bottom billion through control of neglected tropical diseases. Lancet 2009;373:1570-5.

2. Hall A, Hewitt G, Tuffrey V, de Silva N. A review and meta-analysis of the impact of intestinal worms on child growth and nutrition. Matern Child Nutr 2008;4:118-236.

3. Raza HH, Sami RA. Epidemiological study on gastro-intestinal parasites among different sexes, occupations and age groups in Sulaimani district. J Duhok Univ 2009;12:317-23.

4. Rashid MK, Joshi M, Joshi HS. Prevalence of intes-tinal parasites among school going children in Bareilly district. Natl J Integr Res Med 2011;2:35-7.

5. Garcia LS. Diagnostic Medical Parasitology. $5^{\text {th }}$ ed. Washington DC: ASM Press; 2007.

6. Ahmed NH, Chowdhary A. Comparison of different methods of detection of enteric pathogenic protozoa. Indian J Med Microbiol 2013;31:154-60.

7. Singh R, Singla P, Sharma M, Aparna, Chaudhary U. Prevalence of intestinal parasitic infections in a Tertiary Care Hospital in Northern India: Five year retrospective study. Int J Curr Microbiol App Sci 2013;2:112-7

8. Kang G, Mathew MS, Rajan DP, Daniel JD, Mathan MM, Mathan VI, et al. Prevalence of intestinal parasites in rural Southern Indians. Trop Med Int Health 1998;3:70-5.

9. Kotian S, Sharma M, Juyal D, Sharma N. Intestinal parasitic infection intensity, prevalence and associated risk factors, a study in the general population from the Uttarakhand hills. Int J Med Public Health 2014;4:422-5.

10. Kumar H, Jain K, Jain R. A study of prevalence of intestinal worm infestation and efficacy of anti-helminthic drugs. Med J Armed Forces India 2014;70:144-8

11. Parameshwarappa KD, Chandrakanth C, Sunil B. The prevalence of intestinal parasitic infestations and the evaluation of different concentration techniques of the stool examination. J Clin Diag Res 2012;6:1188-91.

12. Champa H, Sreeshma P. Intestinal parasitic infections among patients attending a Teritiary Care hospital in South India. J Evol Med Dent Sci 2012;1:308-14.

13. Patel MM, Patel PR, Gamit B, Modi J, Padsala S. Prevalence of intestinal parasites infestation in Surat city of South Gujarat: A hospital based study. Natl J Community Med 2014:5:273-5.

14. Kumar R, Biswas PP, Yasmin T, Sen A. Prevalence of intestinal parasitic infections in patients attending a Tertiary Care Hospital in Eastern Bihar. J Evol Med Dent Sci 2014;3:6740-6.

15. Choubisa SL, Jaroli VJ, Choubisa P, Mogra N. Intestinal parasitic infection in Bhil tribe of Rajasthan, India. J Parasit Dis 2012;36:143-8.

16. Kavathia G, Pattani M, Chaudhary A, Joshi T, Mehta K. A prevalence study of intestinal parasitic infections in symptomatic children at Tertiary Care Hospital in Rajkot city of Gujarat (India) IOSR J Dent Med Sci 2016;15:13-5.

17. Purbey MK, Banerjee T. Spectrum of intestinal parasitic infections (IPIs) in a Tertiary Care Hospital in Varanasi: Need to protect school aged children from giardia infection. Natl J Lab Med 2017;6:MO01-5.

18. Hardie RM, Wall PG, Gott P, Bardhan M, Bartlett LR. Infectious diarrhea in tourists staying in a resort hotel. Emerg Infect Dis 1999;5:168-71.

19. Mathuria YP, Singh A. Prevalence of intestinal parasites at a tertiary care center at Moradabad, Western Uttar Pradesh, India: A one-year 
observational study. Ann Int Med Dent Res 2017;3:MB07-10.

20. Ramana KV, Mohanty SK. Opportunistic intestinal parasites and TCD4+cell counts in human immunodeficiency virus seropositive patients. J Med Microbiol 2009;58:1664-6.
21. Vyas N, Sood S, SharmaB, Kumar M. The prevalence of intestinal parasitic infestation and the related profile of the CD4(+) counts in HIV/AIDS people with diarrhoea in Jaipur city. J Clin Diagn Res 2013;7:454-6 